\title{
Applicability of video-derived bathymetry estimates to nearshore current model predictions
}

\author{
Max Radermacher $\uparrow$, Meagan Wengrove $\ddagger$, Jaap van Thiel de Vries $\uparrow$, Rob Holman $\infty$ \\ $\dagger$ Delft University of Technology \\ Faculty of Civil Engineering \\ Stevinweg 1 \\ I University of New Hampshire \\ Durham, NH, U.S.A. \\ med36@wildcats.unh.edu \\ $\infty$ Oregon State University \\ Corvallis, OR, U.S.A. \\ holman@coas.oregonstate.edu
}

2628CN Delft, The Netherlands

m.radermacher@tudelft.nl

j.s.m.vanthieldevries@tudelft.nl

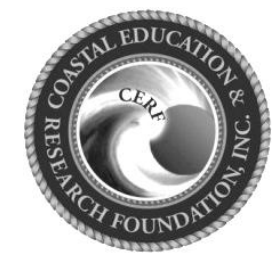

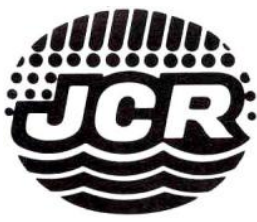

www.JCRonline.org

\section{ABSTRACT}

Radermacher, M., Wengrove, M.E., Van Thiel de Vries, J.S.M., Holman, R.A., 2014. Applicability of video-derived bathymetry estimates to nearshore current model predictions. In: Green, A.N. and Cooper, J.A.G. (eds.), Proceedings $13^{\text {th }}$ International Coastal Symposium (Durban, South Africa), Journal of Coastal Research, Special Issue No. 70, pp. 290-295, ISSN 0749-0208.

\begin{abstract}
In the framework of swimmer safety, coastal managers desire accurate nearshore current predictions obtained from numerical models. To this end, detailed and up-to-date bathymetry is a necessity. Remote sensing techniques for bathymetry estimation are a promising solution. The focus of this paper is to assess the performance of wavenumberbased bathymetric inversion using Argus imagery (also known as the cBathy algorithm) as a feasible input bathymetry for numerical models to make reasonable nearshore current predictions. Numerical flow simulations on a cBathy bed are compared to simulations on an in-situ surveyed bathymetry. Results demonstrate that simulated nearshore currents on a cBathy bathymetry have a root-mean-square error in the order of $10 \mathrm{~cm} / \mathrm{s}$ (magnitude) and 40 degrees (direction) when compared to simulated currents on a surveyed bathymetry. In the intertidal zone cBathy should be combined with a different method for bathymetry estimation in order to decrease these errors.
\end{abstract}

ADDITIONAL INDEX WORDS: Remote sensing, Argus, Numerical modeling, Sand Motor, Swimmer safety.

\section{INTRODUCTION}

In the nearshore, many processes are strongly influenced by the bed topography. Surfzone currents, which are studied here in relation to swimmer safety, are a clear example. The beach profile has its influence on the cross-shore distribution of currents (Ruessink et al., 2001), whereas alongshore variable bar patterns may induce rip cell circulations (Dalrymple et al., 2011). As a result of wave and current action, the bed is highly dynamic and bathymetry will change continuously. Such that there is a great need for frequent bathymetric data of the nearshore.

In-situ survey methods, such as echo sounders attached to floating equipment, are accurate and can be used for any desired spatial resolution. However, their maintenance and costs inhibit the implementation of high-frequency operational survey schedules. In contrast, remote sensing (RS) survey methods have a lower accuracy and limited spatial resolution, but are much less time-consuming and have low operational costs. The survey purpose determines if the accuracy and resolution achieved by a specific RS method are sufficient.

The relation between surfzone currents and bathymetry is not trivial, in that significant bathymetric errors do not necessarily lead to low accuracy in calculated currents on top of the bed. A bathymetry can be thought to consist of various features of different length scales, superimposed on each other. Through the

DOI: 10.2112/SI70-049.1 received 28 November 2013; accepted 21 February 2014. @ Coastal Education \& Research Foundation 2014 use of smoothing, Plant et al. (2009) assessed the influence of these bathymetric length scales on numerically simulated flow fields. They concluded that alongshore variability of intermediate scale features, associated with sand bar patterns, has a particularly strong influence. In this paper, the applicability of the cBathy algorithm (Holman et al., 2013), based on the Argus system for coastal imagery (Holman and Stanley, 2007), to nearshore current simulations is explored. The capability of this method to resolve sand bar patterns is hypothesized to be crucial for accurate model predictions of nearshore currents.

\section{METHODS}

cBathy results are obtained from the Sand Motor Argus station in the Netherlands. The Sand Motor (also known as Sand Engine or Zandmotor) is a vast beach nourishment of approximately 20 $\mathrm{Mm}^{3}$ near the town of Ter Heijde, which primarily serves as a means of coastal protection against flooding (Stive et al., 2013). In this study, one bathymetric survey conducted between 1 and 4 July 2013 is used for groundtruth comparison. In-situ bathymetry is measured using RTK-DGPS and a single-beam echo sounder (SBES) mounted on a personal water craft (PWC) for the wet section of the beach profile and an RTK-DGPS mounted on an allterrain vehicle (ATV) for the dry section. With a comparable PWC-mounted system, MacMahan (2001) found that the rootmean-squared (RMS) deviation with respect to measurements by a traditional coastal survey vessel remain below $6 \mathrm{~cm}$. The error 


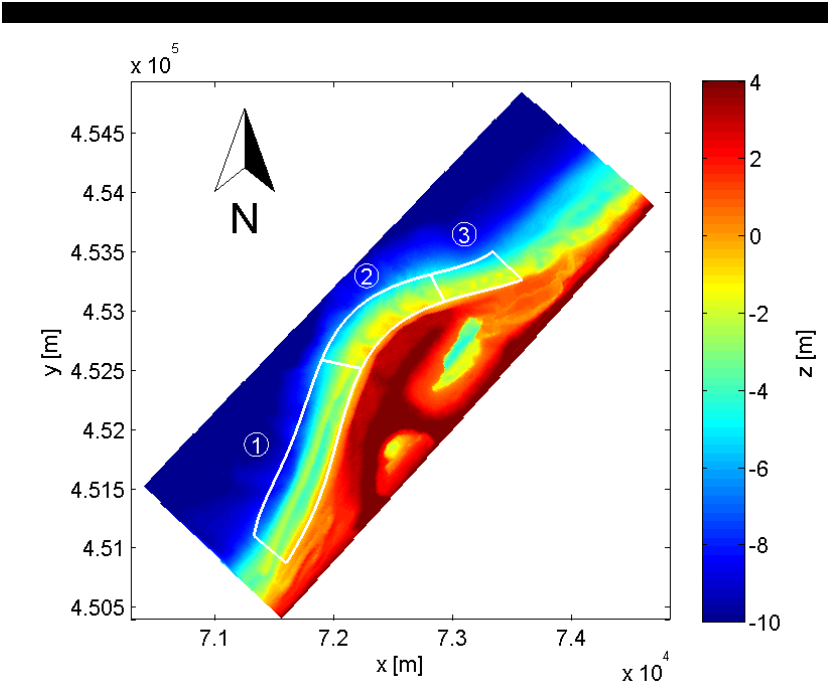

Figure 1. Bathymetry of the Sand Motor as captured during the July 2013 in-situ survey. Horizontal coordinates are according to the Dutch RD system; elevations with respect to the Dutch datum NAP. Numbers indicate nearshore subdomains used in this paper.

margin for the ATV is even smaller, as it is not susceptible to wave response or deviations due to the SBES.

The cBathy algorithm subjects wave-induced modulations of camera pixel intensity to cross-spectral analysis and complex EOF analysis in order to derive frequency and wavenumber pairs over a spatial analysis array. Inversion of the linear dispersion relation subsequently yields estimates of the water depth. Robustness of the algorithm is promoted by Kalman filtering in time (Kalman, 1960).

cBathy estimates are collected every 4 hours, so here both the highest and the lowest skill bathymetry (when comparing cBathy results to the in-situ measurements) during this 4-day period are assessed. Recent studies have reported average cBathy RMS errors (with respect to in-situ surveys) of $0.51 \mathrm{~m}$ for Duck, NC, $0.56 \mathrm{~m}$ for Agate Beach, OR (Holman et al., 2013) and $1.14 \mathrm{~m}$ for
Kijkduin in the Netherlands (Wengrove et al., 2013), the latter based on individual estimates before application of the Kalman filter.

A rectified and merged plan view image created from the 8 installed Argus cameras is presented as Figure 2. cBathy provides depth estimates at an analysis grid with a spacing of $10 \mathrm{~m}$ in the cross-shore and $20 \mathrm{~m}$ in the alongshore direction, contained within the white shape in the figure. As a result of noise, new estimates cannot be given every 4 hours for the full analysis domain. Over the first four days of July 2013 an average return rate of $42 \%$ of all analysis points was achieved, with a maximum of $85 \%$ and a minimum of $9 \%$. Because of the relatively large cBathy analysis domain at the Sand Motor, combined with a low graze angle, average return rates reported by Holman et al. (2013) are much higher: $84 \%$ at Duck (small analysis domain) and approximately $85 \%$ at Agate Beach (high graze angle). Using the Kalman filtering procedure, effectively a running average of depth estimates is computed in time, bridging the gaps created by return rates less than $100 \%$.

The bathymetries obtained from this analysis procedure are not directly applicable in numerical flow simulations. Especially in the off-shore regions, approximately outside the $6 \mathrm{~m}$ depth contour, moving objects in the camera images like small craft vessels and drifting navigation buoys are a very coherent source of errors. They are erroneously interpreted as wave-like signals by the cBathy algorithm, typically resulting in very shallow depth estimates with a high confidence. This problem is partly mitigated by rejecting depth estimates resulting from the lowest frequencies used in the analysis, as these tend to contain most of the energy associated with the errors. Furthermore, analysis tiles including pixels on the dry beach create deep troughs near the shoreline. Finally, only cBathy estimates that fall inside the three nearshore regions of Figure 1 (approximately the first 500 meters from the shoreline) are incorporated in the input bathymetry. The rest of the domain is filled with data from the in-situ survey, as cBathy results are too contaminated in these regions.

Numerical flow simulations on top of a cBathy bed are compared to simulations using a groundtruth bathymetry. The latter is assumed here to be the 'target': cBathy is judged suitable for nearshore current simulations if flow simulation results on both bathymetries compare well. The Delft3D suite (Lesser et al.,

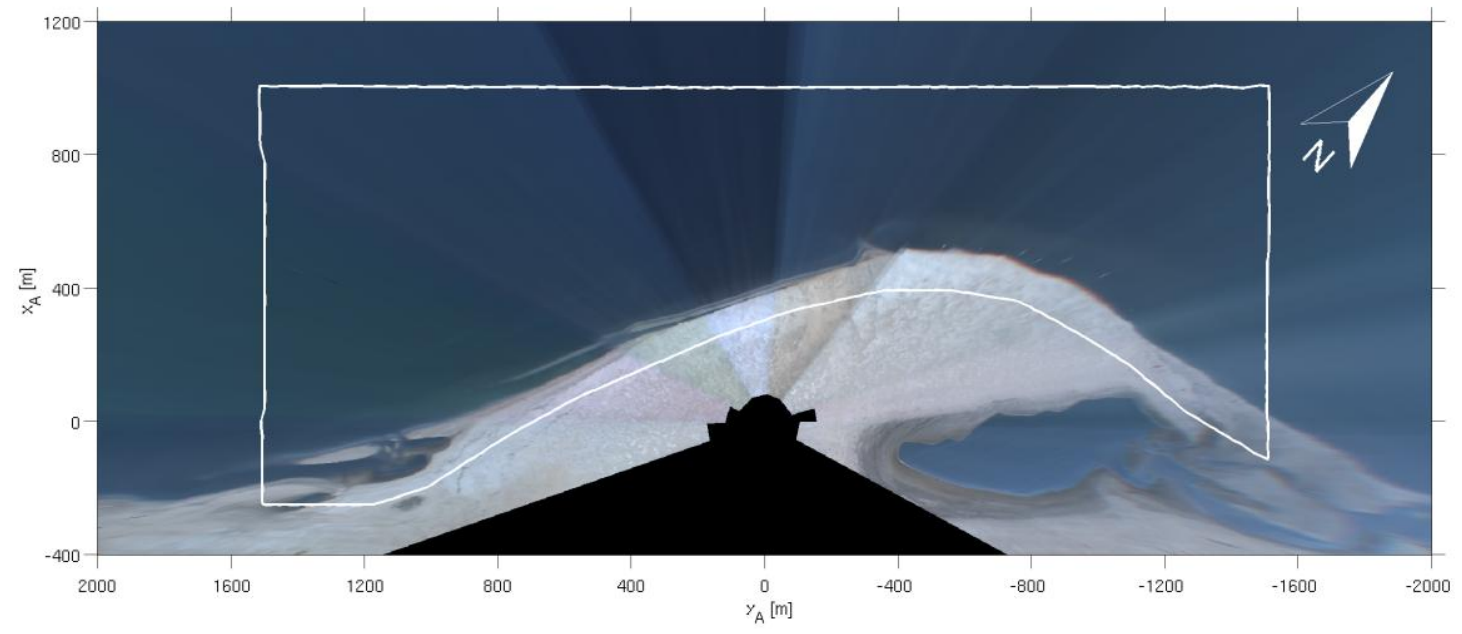

Figure 2. Merged and rectified (i.e. plan view) image of the Sand Motor collected by the Argus station at the Sand Motor on 8 July 2013. The initially hook-shaped peninsula shows clear signs of gross sediment fluxes in both northward and southward direction since construction was completed in fall 2011. The white polygon indicates the extent of the cBathy pixel grid. Horizontal coordinates are in the local Argus coordinate system. 
2004) is used to conduct the flow calculations. This model has been used before to study nearshore currents over complex bathymetries, e.g. by Smit et al. (2008), Garcia et al. (2013) and Van Dongeren et al. (2013). The Sand Motor is embedded in a rectangular computational grid covering roughly $9.6 \times 3.8 \mathrm{~km}$ in the alongshore and cross-shore directions respectively. The grid cell resolution varies from $50 \mathrm{~m} \times 50 \mathrm{~m}$ in the offshore corners towards $17 \mathrm{~m} \mathrm{x} 17 \mathrm{~m}$ in the region of interest.

Both bathymetric data sources are interpolated to the numerical grid, but first a limited amount of smoothing is added to the cBathy data on a uniform $17 \mathrm{~m} \times 17 \mathrm{~m}$ grid using a Hanning filter with a length of $17 \mathrm{~m}$ in all directions to reduce potential aliasing of sub-grid scale features (Plant et al., 2009), to average out noise in the cBathy bed and to provide a smooth transition at the edge of the nearshore subdomains. Although the cBathy algorithm already introduces a similar amount of smoothing (Holman et al., 2013), RMS error statistics showed a significant improvement after applying this additional, limited amount of smoothing.

Boundary conditions are obtained from the operational Coastal Storm Modelling System (CoSMoS; Van Ormondt et al. 2012). This train of numerical wave and flow models is driven at the highest level by wave predictions for the Atlantic Ocean from NOAA's WaveWatch III model, meteorological predictions from the High Resolution Limited Area Model (HIRLAM) and astronomic water level predictions from the TPXO 6.2 model. More detailed models are nested down to the desired grid cell size at the Dutch coast. Finally, CoSMoS provides directional wave spectra, water levels and water level gradients to the Sand Motor model's boundaries and initial conditions.

Boundary conditions from the four days of the groundtruth survey have not been used, because accurate measurements with the single-beam echo sounder require mild hydrodynamic conditions $\left(\mathrm{H}_{\mathrm{s}}<0.5 \mathrm{~m}\right)$ in order to limit dynamic response of the PWC. This inhibits analysis of rip current formation on the cBathy bed, which would be an interesting process to study given the swimmer safety background of this research, as these currents only develop with sufficient wave-forcing. Hence boundary conditions have been taken from the last three days of June, when hydrodynamics were slightly more energetic (waves with $\mathrm{H}_{\mathrm{s}} \approx 1$ and directions between $\mathrm{NW}$ and $\mathrm{N}$ ). The westerly wind is moderate, with an average speed of $6.1 \mathrm{~m} / \mathrm{s}$ and a maximum of 9.4 $\mathrm{m} / \mathrm{s}$ computed by HIRLAM.

\section{RESULTS}

In this section, first the cBathy depth estimates are compared to the groundtruth target bathymetries in order to select the best and worst matching 4-hourly cBathy results during the 4-day groundtruth survey campaign. Secondly, the results of the flow simulations are presented.

\section{Bathymetry}

Figure 1 shows the bathymetry of the Sand Motor as captured during the groundtruth survey campaign of 1 to 4 July 2013. In the alongshore direction, three distinct regions can be indicated based on the prevailing bathymetric features. The southernmost region is characterized by a single, alongshore uniform bar (subdomain 1 in Figure 1). At the most seaward part of the Sand Motor, the bar welds to the shoreline and forms wide transverse bars incised by pronounced channels (subdomain 2). Along the spit towards the inlet of the lagoon, more rhythmic bar patterns can be distinguished (subdomain 3). Due to all these different regions, simulated flow patterns are also expected to show interesting spatial variability.

Because the in-situ bathymetric survey was conducted over a 4 day period, the RMS error over time is assessed to choose which cBathy estimate during this period best matches the PWC bathymetry. In the development of the RMS error over time a slight trend is present, with a minimum error around 3 July. This trend is very likely to be the result of noise rather than natural morphological evolution, as environmental conditions were very mild during the first four days of July and longer term development of RMSE shows a more scattered behavior rather than a smooth development. Errors in the nearshore domain (Figure 1) range from $48-66 \mathrm{~cm}$. The collective RMS error over the three nearshore regions was used to rank the 4-hourly cBathy estimates. Both the highest (0.48 $\mathrm{m}$ at 2 July 18:40 UTC) and the

lowest ranked (0.66 $\mathrm{m}$ at 4 July 10:40 UTC) estimates were applied in the numerical modeling phase, as to represent the full range of results. The presented RMS errors in the nearshore are
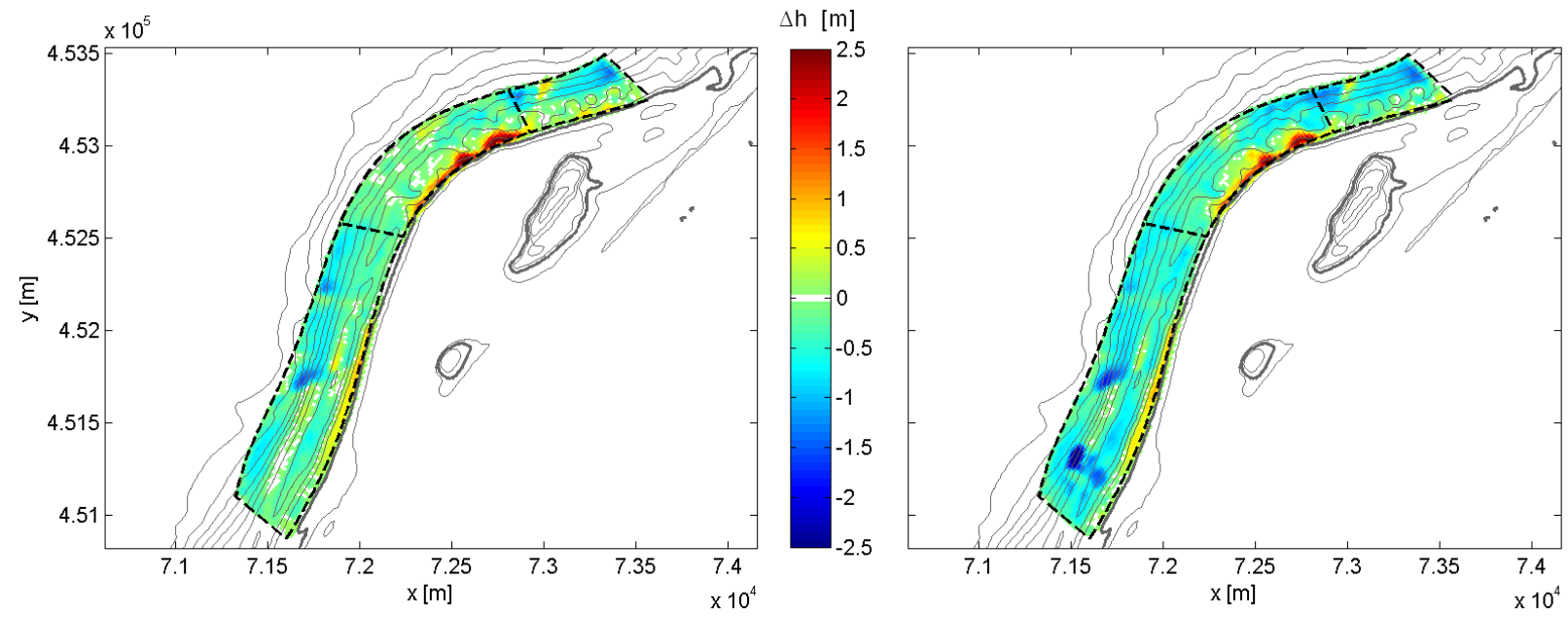

Figure 3. Highest (left) and lowest (right) ranked cBathy results. Both panels show deviations of cBathy bed levels with respect to groundtruth (red indicating cBathy estimate is too deep) together with depth contours of the groundtruth bathymetry. Outside the nearshore domains differences are absent, since cBathy estimates are omitted there. 
comparable to those found by Holman et al. (2013), as mentioned in the previous section.

The spatial distribution of deviations of the highest ranked cBathy estimate are shown in the left panel of Figure 3. The calculated differences between the cBathy estimate and the in-situ survey demonstrate that $\mathrm{cBathy}$ resolves the seaward side to be too shallow and the shoreward side to be too deep (maximum deviations up to $\pm 2.5 \mathrm{~m}$ ), in accordance with results from Holman et al. (2013) and Wengrove et al. (2013). This is highly noticeable in the upper part of the shore-connected bars in subdomain 2, where a trough separates the bar from the shoreline. Also, the southernmost rip channel in subdomain 2 is estimated to be too shallow by $50 \mathrm{~cm}$, which could be the result of strong wavecurrent interaction when rips are active. The right panel of Figure 3 represents the lowest ranked (or worst) cBathy estimate. The error patterns are comparable, but the absolute deviations are larger. In subdomain 1 an erroneous shore-connected bar appears, whereas alongshore variability in subdomain 3 almost vanishes.

\section{Nearshore currents}

The simulation results are summarized in Figure 4. It shows the temporal development of the RMSE in both magnitude (middle panel) and direction (lower panel) of currents on a cBathy bed with respect to currents on a groundtruth bathymetry. Modeled timeseries of environmental conditions, depicted in the upper panel, were obtained from a location offshore of subdomain 2 . Altogether the velocity RMS errors remain below $15 \mathrm{~cm} / \mathrm{s}$ in all subdomains for both the best and the worst cBathy result. The figure shows a clear tidal modulation, which peaks during low water.

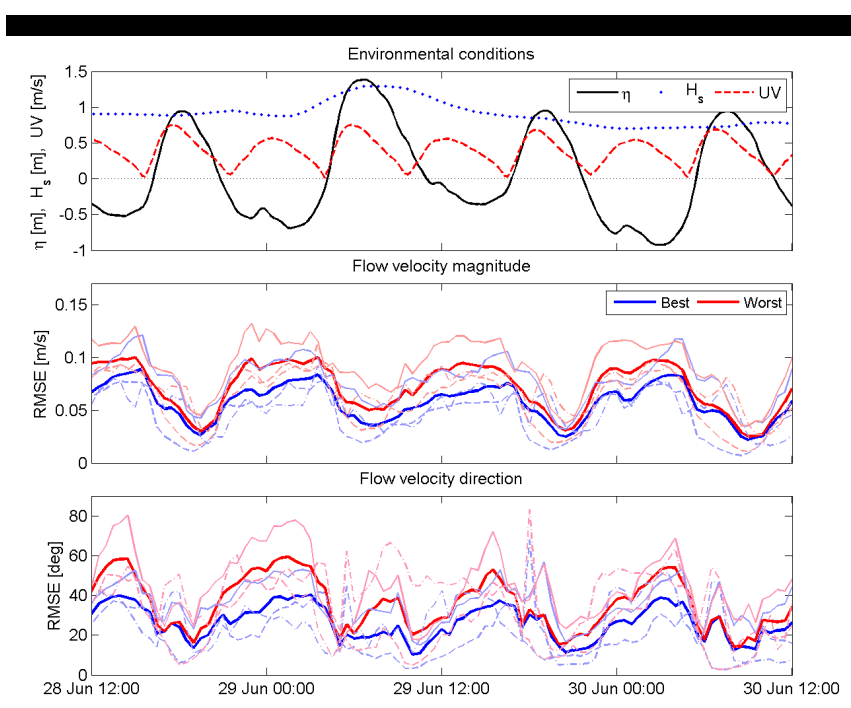

Figure 4. Environmental conditions as observed offshore of subdomain 2: tidal elevation $\eta$, significant wave height $H_{s}$ and flow velocity magnitude $U V$ (upper panel). Root-mean-square errors of flow velocity magnitude (middle panel) and direction (lower panel), using the best (blue) and worst (red) cBathy results. Individual subdomains are shown in thin, shaded lines: subdomain 1 (dashed), subdomain 2 (solid) and subdomain 3 (dash-dotted).

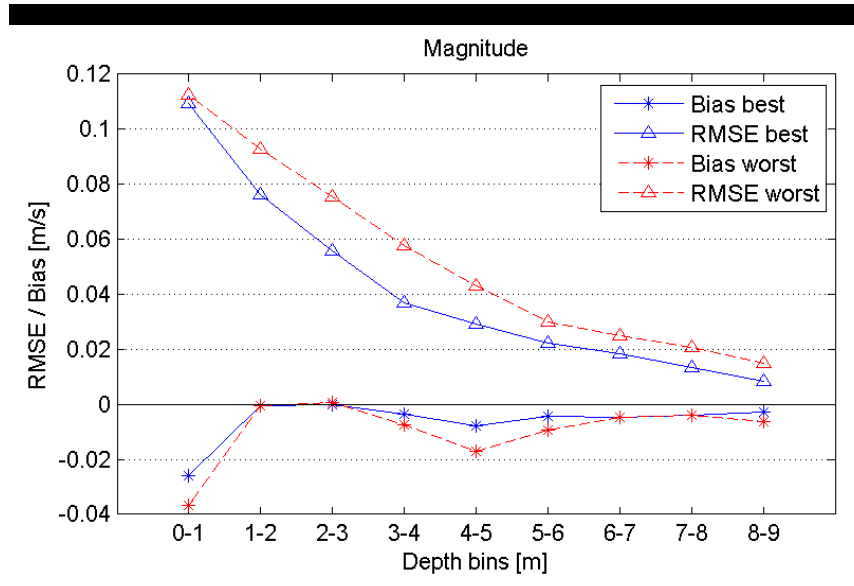

Figure 5. Time-averaged bias (stars) and RMS errors (triangles) of current magnitude deviations per (PWC) depth bin. Values based on the best cBathy estimate are shown in solid blue lines, those based on the worst estimate are shown in dashed red lines.

Figure 4 showed domain-averaged error statistics over time. In order to assess the spatial distribution of these errors, they can also be presented in a time-averaged plot. In Figure 5, bias and RMSE are shown per depth bin and averaged over time. It becomes apparent that the biggest error sources reside near the shoreline, as the shallowest depth bins have the highest bias and RMSE. To take the tidal modulation (Figure 4) into account, separate timeaveraged statistics were calculated for the high water (HW, $\eta>0$ ) and low water (LW, $\eta<0)$ phase. The HW-averaged statistics are rather straightforward (not shown here): subdomain 1 and 2 are dominated by an alongshore tidal current, which shows only very small deviations between both bathymetries. In subdomain 3, errors between currents on the cBathy and PWC bed are somewhat larger, due to the separation of tidal flow and the associated formation of a gyre. The LW- averaged statistics for the best bathymetry are shown in the left column of Figure 6. In subdomain 1 , there is a small offset in the shore-parallel current through the longshore trough, which clearly shows from the adjacent red and blue bands in the middle panel. Shifting the focus to subdomain 2, good agreement between both simulations in the two distinct rip channels can be observed. Only the feeder currents near the shoreline show relatively large deviations, obviously resulting from the coarse overestimation of water depth by cBathy in the intertidal zone (recall Figure 3). This mainly goes for the northernmost part of subdomain 2 , where the trough estimated by cBathy is particularly deep and flow directions deviate accordingly. In subdomain 3 there is again good agreement between both simulations, judging from the small differences in magnitude and direction. The rhythmic bar patterns do not seem to evoke strong rip currents, but the slightly off-shore directed flow in the eastern part of the subdomain is well represented.

The flow field obtained with the worst bathymetry is less capable of reproducing the flow field on a groundtruth bed. HWaveraged statistics do not show a large additional error, as this tidal phase is dominated by a strong shore-parallel tidal current, which is less influenced by bar patterns. Deviations in magnitude during HW are slightly higher compared to those of the highest ranked bathymetry, due to the more pronounced underestimation of water depth on the outer bar face by cBathy (Figure 3). LWaveraged statistics are shown in the right column of Figure 6. Observed deviations in subdomain 1 computed with the worst cBathy estimate (offset of current through longshore trough) are 

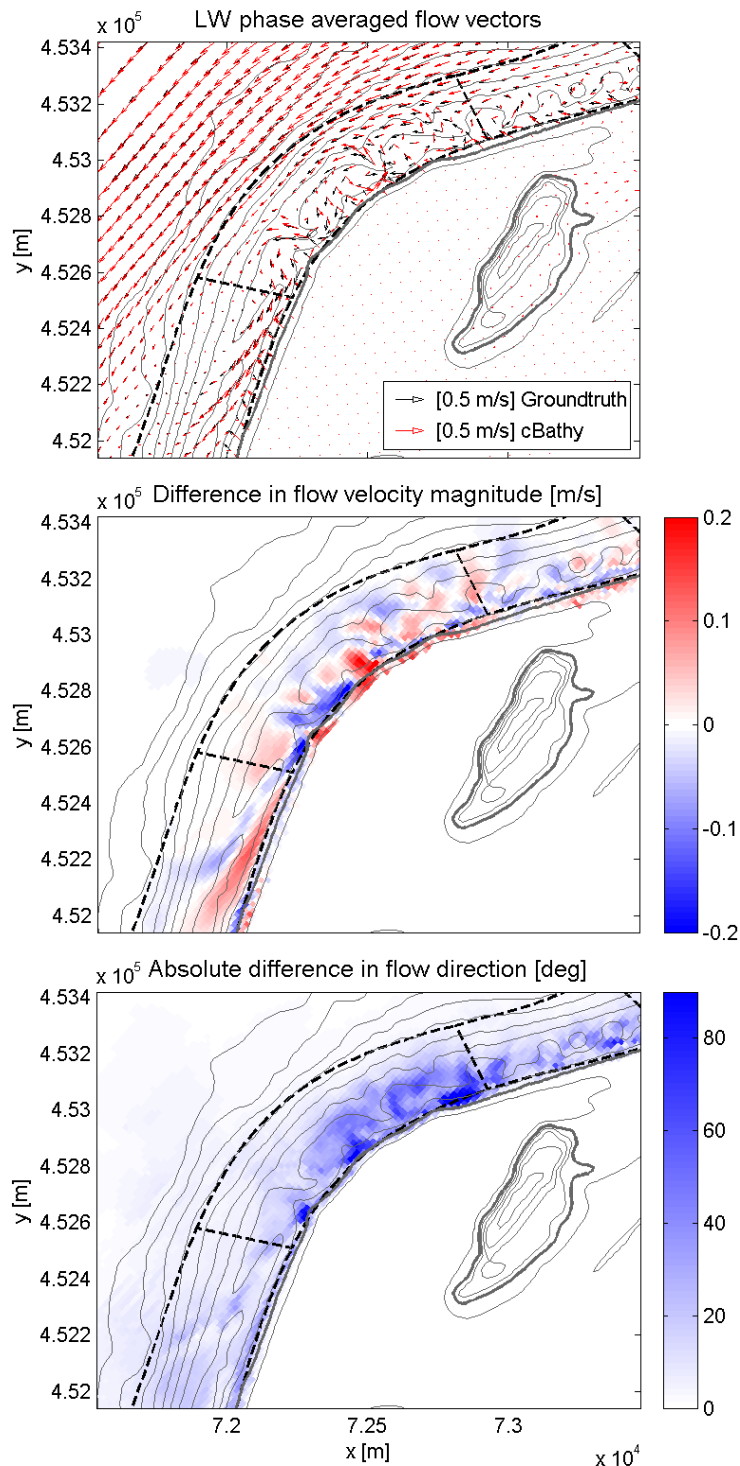

LW phase averaged flow vectors

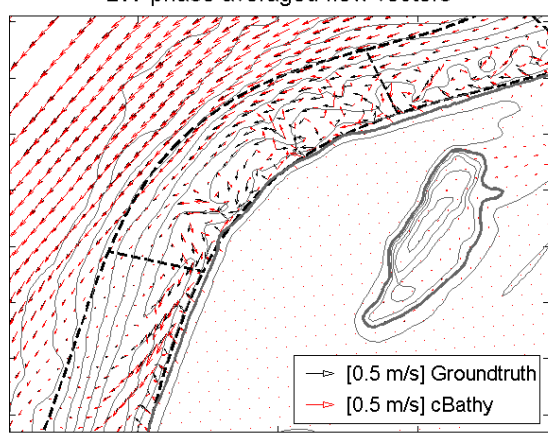

Difference in flow velocity magnitude $[\mathrm{m} / \mathrm{s}]$

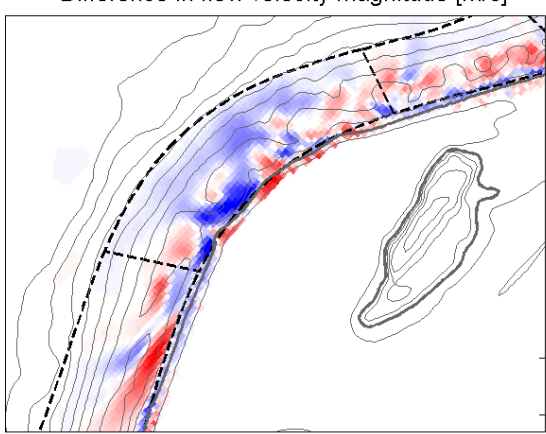

Absolute difference in flow direction [deg]

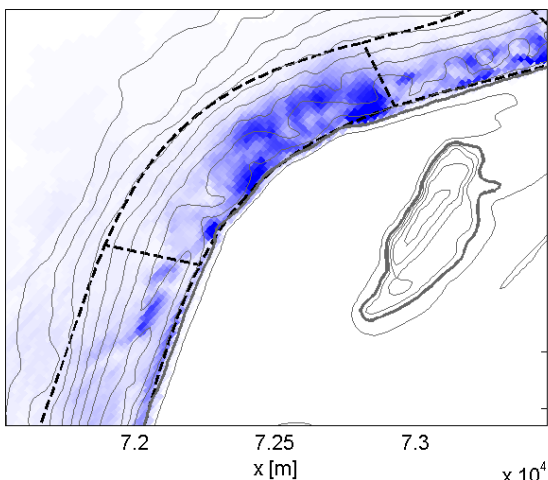

Figure 6. Comparison of low water phase-averaged currents over a cBathy bed (left column for best estimate, right column for worst estimate) and groundtruth bathymetry. The upper panels show velocity vectors (red for cBathy, black for groundtruth; only 1 in every 3 arrows is shown), the middle panels show the difference in magnitude (red indicating overestimation of velocities using a cBathy bed) and the lower panels show the absolute difference in direction. Grey contour lines represent the groundtruth bathymetry.

similar to those computed with the best cBathy estimate, but stronger. In subdomain 2, the rip current in the lower left channel is still well predicted using the worst estimate. This does not hold for the upper right part of this subdomain, where the trough near the shoreline is deeper than in the best estimate and completely disturbs the flow field. This influences currents in the left part of subdomain 3 as well, resulting in larger deviations.

\section{DISCUSSION}

Results show velocity deviations simulated on the best cBathy bed averaged over HW and LW tidal phases remain below 10 $\mathrm{cm} / \mathrm{s}$, except for several locations close to the shoreline, where deviations reach up to $20 \mathrm{~cm} / \mathrm{s}$ during $\mathrm{LW}$. When compared to maximum flood currents of $70 \mathrm{~cm} / \mathrm{s}$ and maximum ebb currents of $55 \mathrm{~cm} / \mathrm{s}$ at $13 \mathrm{~m}$ water depth (see upper panel of Figure 4) and about $50 \mathrm{~cm} / \mathrm{s}$ in the nearshore (which also happens to be the order of magnitude of human swimming speed), these deviations seem reasonably small. Using the worst cBathy bed, flow fields compare less well and deviations increase over the full nearshore domain. Generally, the tidal modulation of the error can potentially be explained by the increasing relative importance of absolute errors in the cBathy bed as the water level decreases, or could be related to specific features in the flow field during the subsequent tidal phases. When the flood phase is initiated, a uniform current develops along the shoreline, directed to the North-East. At the lee-side of the Sand Motor, this causes flow separation and the creation of a large-scale gyre near subdomain 3. Before the gyre gets advected northward, the ebb phase commences and the gyre dies out. During the ebb phase, lowering of the water level causes waves to break over the prominent transverse bars in subdomain 2. In line with rip current theory and observations, this drives strong seaward currents in the rip channels (Dalrymple et al., 2011). Although the rips are resolved well in both magnitude and direction on the cBathy bed, directional RMSE peaks up to 80 degrees in subdomain 2 for the 
worst bathymetry (lower panel of Figure 4). This is mainly caused by differences in nearshore circulations on the cBathy and PWC bed, locally leading to directional deviations around 180 degrees. The ebb flow again creates a gyre, which is now located southwest of the Sand Motor and partly passes through subdomain 1. Subsequently the flood phase sets in and the cycle starts over.

Similar flow simulations for the first four days of July, when environmental conditions were very mild, yielded smaller deviations. In an operational current forecasting scheme, e.g. for swimmer safety purposes, even the worst cBathy estimate combined with highly energetic environmental conditions should yield flow errors that remain within acceptable limits. More extreme environmental conditions and bathymetric deviations will be explored in more detail in follow-up research.

Improving remotely sensed bathymetric estimates near the shoreline is expected to reduce errors in flow predictions. cBathy estimates several troughs in the intertidal zone that do not only disturb the calculated flow at those locations, but also influence a wider region (in the order of 10's to 100's of meters). An example of this relates to erroneous predictions of a feeder current effecting the strength and timing of the associated rip current. An Argusbased tool for the estimation of intertidal bathymetry using shoreline tracking has been described by Aarninkhof et al. (2003) and Uunk et al. (2010). Future research will focus on incorporating this source of up-to-date RS bathymetry in the numerical model simulations. Another possible solution strategy would be to reduce anomalies in the cBathy bed through the use of smoothing, thereby partly removing the troughs. Additional simulations have been conducted with a smoothed bathymetry, using a Hanning window which spans 4 surrounding grid cells in both horizontal dimensions (Plant et al., 2009). Although error statistics of this smoother bathymetry show a slight decrease of RMSE in flow magnitude and direction, important flow features to hydrodynamic predictions for swimmer safety purposes like rip currents are damped through the removal of rip channels.

This research has only focused on model-model comparison of bathymetries and flow fields so far, because an extensive set of hydrodynamic field data around the Sand Motor is currently lacking. During the MegaPEX field campaign in fall 2014 a robust dataset of hydrodynamic conditions will be collected, that can be used to validate hydrodynamic model simulations.

\section{CONCLUSIONS}

In this paper, a comparison has been presented between remotely sensed bathymetric data obtained with the cBathy algorithm and groundtruth bathymetric data of the Sand Motor, as well as a comparison of flow fields simulated on these bathymetries using a 2DH hydrodynamic model. Despite considerable root-mean-squared errors in the depth estimates, cBathy bathymetries generally induced fairly small deviations in the flow field. The main source of errors resides around the shoreline, where the water depth is heavily overestimated by cBathy.

In conclusion, cBathy seems to be a suitable tool for application in operational nearshore current predictions. However, please note that depth estimates for deeper parts of the analysis domain (all data from the area indicated in Figure 2 that fall outside the nearshore domains indicated in Figure 1) have been rejected in the final bathymetry.

\section{ACKNOWLEDGEMENTS}

Max Radermacher is supported by STW Perspectief program Nature-driven nourishments of coastal systems (NatureCoast), project 12686: S1 Coastal Safety. The authors would like to acknowledge Roderik Hoekstra and Cilia Swinkels from Deltares for providing the basis of the Delft3D model used in this research, along with the associated CoSMoS boundary conditions.

\section{LITERATURE CITED}

Aarninkhof, S.G.J., Turner, I.L., Dronkers, T.D.T., Caljouw, M. and Nipius, L., 2003. A video-based technique for mapping intertidal beach bathymetry. Coastal Engineering, 49, 275-289.

Dalrymple, R.A., MacMahan, J.H., Reniers, A.J.H.M. and Nelko, V., 2011. Rip currents. Annual Review of Fluid Mechanics, 43, 551-581.

Garcia, I.D., El Serafy, G., Heemink, A. and Schuttelaars, H., 2013. Towards a data assimilation system for morphodynamic modeling: bathymetric data assimilation for wave property estimation. Ocean Dynamics, 63, 489-505.

Holman, R.A. and Stanley, J., 2007. The history and technical capabilities of Argus. Coastal Engineering, 54, 477-491.

Holman, R.A., Plant, N.G. and Holland, K.T., 2013. cBathy: A robust algorithm for estimating nearshore bathymetry. Journal of Geophysical Research: Oceans, 118, 2595-2609.

Kalman, R., 1960. A new approach to linear filtering and prediction problems. Journal of Basic Engineering, 82, 35-45.

Lesser, G.R., Roelvink, J.A., Van Kester, J.A.T.M. and Stelling, G.S., 2004. Development and validation of a three-dimensional morphological model. Coastal Engineering, 51, 883-915.

MacMahan, J.H., 2001. Hydrographic surveying from personal watercraft. Journal of Surveying Engineering, 127, 12-24.

Plant, N.G., Edwards, K.L., Kaihatu, J.M., Veeramony, J., Hsu, L. and Holland, K.T., 2009. The effect of bathymetric filtering on nearshore process model results. Coastal Engineering, 56, 484-493.

Ruessink, B.G., Miles, J.R., Feddersen, F., Guza, R.T. and Elgar, S., 2001. Modeling the alongshore current on barred beaches. Journal of Geophysical Research, 106, 22,451-22,463.

Smit, M.W.J., Reniers, A.J.H.M., Ruessink, B.G. and Roelvink, J.A., 2008. The morphological response of a nearshore double sandbar system to constant wave forcing. Coastal Engineering, 55, 761-770.

Stive, M.J.F., De Schipper, M.A., Luijendijk, A.P., Aarninkhof, S.G.J., Van Gelder-Maas, C., Van Thiel de Vries, J.S.M., De Vries, S., Henriquez, M., Marx, S. and Ranasinghe, R., 2013. A new alternative to saving our beaches from sea-level rise: the Sand Engine. Journal of Coastal Research, 29, 1,001-1,008.

Uunk, L., Wijnberg, K.M. and Morelissen, R., 2010. Automated mapping of the intertidal beach bathymetry from video images. Coastal Engineering, 57, 461-469.

Van Dongeren, A., Van Ormondt, M., Sembiring, L., Sasso, R., Austin, M., Briere, C., Swinkels, C., Roelvink, D. and Van Thiel de Vries, J., 2013. Rip current predictions through model-data assimilation on two distinct beaches. In: Proceedings of the Coastal Dynamics 2013 conference (Arcachon, France).

Van Ormondt, M., Van Dongeren, A., Briere, C., Sembiring, L., Winter, G., Lescinski, J. and Swinkels, C., 2012. Simulating storm impacts and coastal flooding along the Netherlands coast. In: Klijn, F. and Schwenkendiek, T. (eds.), Comprehensive Flood Risk Management. Proceedings of the Flood Risk 2012 conference (Rotterdam, Netherlands).

Wengrove, M.E., Henriquez, M., De Schipper, M.A., Holman, R.A. and Stive, M.J.F., 2013. Monitoring morphology of the Sand Engine leeside using Argus' cBathy. In: Proceedings of Coastal Dynamics 2013 (Arcachon, France), 1893-1904. 